\title{
Influence of Retention Strategies on Satisfaction Level of Teachers: A Regression Model
}

Roy Mathew* and S John Manohar ${ }^{\dagger}$

\begin{abstract}
Research has shown that job satisfaction is an antecedent to various factors of retention and holds a strong association with these factors. This study is conducted to know the major factors which influence the teachers to remain in any management institution. The data was collected from 261 teachers from unaided educational institutions in Bengaluru by using a structured questionnaire. Statistical tools used are factor analysis, simple averages, ANOVA and regression. The major factors affecting retention of teachers in management institutions in Bengaluru are Work Environment, Effective Leadership and Empowerment. It was also found that these factors make a significant impact on the satisfaction of teachers.
\end{abstract}

Keywords: Regression, ANOVA, retention, teachers, satisfaction.

\section{Introduction}

In a large number of studies in the area of social sciences, it is found that there are close association factors which influence an

\footnotetext{
* Bharathiar University, Coimbatore, India; roy0807@gmail.com

† BMS College of Engineering, Bengaluru, India;

johnmanohar2011@gmail.com; johnmanohar2004@yahoo.co.in
} 
employee to stay in an organisation, their relationship with supervisors and working environment. According to Herzberg (1959), achievement, recognition and reward are considered to be the intrinsic elements of the job. On the other hand, employee work environment, compensation, superior support, the policy of the organisation, and interpersonal relationships are the extrinsic elements, referred to as "hygiene factors" or "context" factors. All these factors play a significant role in increasing the job satisfaction level of teachers as well, which, consequently, tend to increase the performance level of teachers in higher education.

\section{Factors affecting retention}

Cascio (2003) defines retention as strategies adopted by the organisation to retain the talented employees from leaving the organisation in the form of rewarding good work of employees, providing harmonious working conditions. Based on the literature survey conducted, six critical factors are identified to retain the best talents which are - compensation; job characteristics, effective training and development system, supervisor support, career opportunities and work-life balance policies. Even now money is considered to be the most attractive strategy to lure hightechnology professionals. This study brought in a variety of other factors which would help in retaining teachers in management institutions.

\subsection{Employee empowerment}

Through good empowerment strategies, it is possible that the employee show higher level of obligation to the organisation. It will indirectly have an influence on them to remain in the organisation even when they undergo pressure from others to quit the organisation. In short, the intention to remain or leave the organisation is based on the job satisfaction level among the teachers. An individual with a higher level of job satisfaction tends to remain more committed to the organisation.

\subsection{Work environment}

One of the primary factors in employee retention is considered to be work environment (Zeytinoglu \& Denton, 2005). The work 
environment characteristics in services sector differ significantly from the manufacturing sector. It is because the services sector directly deals with consumers or clients, whereas in the manufacturing sector it is not so (Normann 1986). The interactions between employees and clients or consumers move from the physical to psychological dimension. Psychological work environment consists of workload, decision, support, stressors, latitude and decision, etc. It is the need of the hour to know and recognise the trends in the industry and provide good work environment as required, to keep the employees loyal to their organisation.

\subsection{Effective leadership}

Leadership is a process of motivating and supporting others to do something of their interest, neither because it is required nor because of the fear of consequences of non-compliance. Leadership is thus a process of making others work enthusiastically towards organisational goals and objectives. It is the human factor that binds a group together and motivates them towards organisational goals transforming the group's potentials into reality.

\section{Literature Review}

Kumar \& Bhatia (2011), while researching on job satisfaction among physical education teachers, found that the level of job satisfaction and attitude of the teachers towards teaching is not much affected by gender, marital status, minimum qualification and income group of Physical Education teachers.

Zilli and Zahoor (2012) concluded the study conducted to understand the organisational commitment among teachers by stating that the females had significantly higher level of organisational commitment when compared to male teachers.

Mehta (2012) investigated on job satisfaction among teachers to know whether the perception of job satisfaction among teachers was affected by the type of organisation and by gender. Descriptive analysis was done and this showed that there is a significant difference in the level of job satisfaction of government and private school teachers. 


\section{Research Methodology}

\subsection{Objectives}

1. To understand the factors affecting retention of teachers.

2. To obtain a regression model showing the influence of key factors of retention on the satisfaction level of teachers.

\subsection{Hypotheses of the Study}

1. There is a significant impact of Effective leadership on Satisfaction of teachers

2. There is a significant impact of Empowerment on Satisfaction of teachers

3. There is a significant impact of Work Environment on Satisfaction of teachers

\subsection{Sampling Design}

Quota sampling technique, which is a non-probability sampling technique, is used. Respondents were 261 teachers from various Management Institutions in Bengaluru. This included Assistant Professors, Associate Professors and Professors from unaided colleges and universities in Bengaluru.

\subsection{Scope of the Study}

The study was conducted for a period of 10 months from June 2015 to March 2016.

\subsection{Sources of Data}

Primary data is collected by using structured questionnaire. This included 44 items under ten factors.

\subsection{Limitations of the Study}

a) Responses may not reveal the actual fact for certain questions.

b) The Sample size is restricted, and quota sampling may not give the actual picture. 
Roy and Manohar Influence of Retention Strategies on Satisfaction Level

c) The questionnaire which consists of 64 items, would be lengthy for a person to answer.

\subsection{Data Analysis Tools}

- Factor analysis was used as a dimension deduction technique. Both EFA and CFA were used. The Principal Component Analysis (PCA) was the Extraction method and Direct Oblimin was the Rotation technique.

- Analysis also involves Linear regression and ANOVA. Measures of central tendency and Dispersion were also used.

\section{Data Analysis}

Table 4.1: Mean and Standard Deviation

\begin{tabular}{lccc}
\hline & Mean & Std. Deviation & Analysis N \\
\hline LD 1 & 3.80 & .995 & 261 \\
LD 2 & 3.44 & .953 & 261 \\
LD 3 & 3.91 & .879 & 261 \\
LD 4 & 3.68 & .874 & 261 \\
EMP 1 & 3.95 & .697 & 261 \\
EMP 2 & 3.55 & 1.028 & 261 \\
WE 1 & 3.16 & .950 & 261 \\
WE 2 & 2.66 & .998 & 261 \\
\hline
\end{tabular}

Table 4.2 KMO and Bartlett's Test

\begin{tabular}{llc}
\hline Kaiser-Meyer-Olkin Measure of Sampling Adequacy. & .566 \\
\hline \multirow{3}{*}{ Bartlett's Test of Sphericity } & Approx. Chi-Square & 786.854 \\
& Df & 28 \\
& Sig. & .000 \\
\hline
\end{tabular}


Table 4.3 Total Variance Explained

\begin{tabular}{lcccc}
\hline Component & \multicolumn{3}{c}{ Initial Eigenvalues } & $\begin{array}{c}\text { Rotation Sums } \\
\text { of Squared } \\
\text { Loadings }\end{array}$ \\
\hline 1 & Total & \% of Variance & Cumulative \% & Total \\
2 & 2.815 & 35.183 & 35.183 & 2.794 \\
3 & 1.822 & 22.780 & 57.963 & 1.697 \\
4 & 1.130 & 14.130 & 72.092 & 1.440 \\
5 & .820 & 10.254 & 82.346 & \\
6 & .582 & 7.279 & 89.625 & \\
7 & .437 & 5.468 & 95.093 & \\
8 & .207 & 2.592 & 97.685 & \\
\hline
\end{tabular}

Extraction Method: Principal Component Analysis.

a. When components are correlated, sums of squared loadings cannot be added to obtain a total variance.

Table 4.4: Pattern Matrix

\begin{tabular}{lccc}
\hline & \multicolumn{3}{c}{ Component } \\
& 1 & 2 & 3 \\
\hline LD 2 & .894 & & \\
LD 1 & .885 & & \\
LD 3 & .804 & & \\
LD 4 & .684 & .871 & .840 \\
EMP 2 & & .841 & .753 \\
EMP 1 & & & \\
WE 1 & & & \\
WE 2 & & & \\
\hline
\end{tabular}

Extraction Method: Principal Component Analysis.

Rotation Method: Oblimin with Kaiser normalisation.

a. Rotation converged in 5 iterations.

Table 4.5: Component Correlation Matrix

\begin{tabular}{lccc}
\hline Component & 1 & 2 & 3 \\
\hline 1 & 1.000 & .032 & .078 \\
2 & .032 & 1.000 & .200 \\
3 & .078 & .200 & 1.000 \\
\hline
\end{tabular}

Extraction Method: Principal Component Analysis.

Rotation Method: Oblimin with Kaiser Normalization. 
Table 4.6: ANOVA

\begin{tabular}{llccccc}
\hline & Model & Sum of Squares & Df & Mean Square & F & Sig. \\
\hline \multirow{2}{*}{1} & Regression & 48.032 & 3 & 16.011 & 83.238 & $.000^{\mathrm{b}}$ \\
Residual & 49.434 & 257 & .192 & & \\
& Total & 97.466 & 260 & & & \\
\hline
\end{tabular}

a. Dependent Variable: SAT

b. Predictors: (Constant), W E, LEAD, EMP

Table 4.7: Coefficients

\begin{tabular}{llccccc}
\hline Model & \multicolumn{2}{c}{$\begin{array}{c}\text { Unstandardized } \\
\text { Coefficients } \\
\text { Std. Error }\end{array}$} & $\begin{array}{c}\text { Standardized } \\
\text { Coefficients } \\
\text { Beta }\end{array}$ & T & Sig. \\
\hline \multirow{2}{*}{$\begin{array}{l}\text { B Constant) } \\
1\end{array}$ LEAD } & 1.312 & .198 & & 6.628 & .000 \\
& EMP & .350 & .036 & .436 & 9.733 & .000 \\
& W E & .096 & .036 & .118 & 2.624 & .009 \\
\hline
\end{tabular}

a. Dependent Variable: SAT

\section{Findings and Conclusion}

\subsection{Findings}

1. Pattern Matrix in Table 4.4 reveals that there are three components which contribute to factors affecting retention of teachers, which are i) Effective Leadership II) Empowerment and iii) Work Environment.

Component correlation matrix gave a maximum correlation of only 0.200 between Components 2 and 3 which is Empowerment and Work Environment.

2. From Table 4.7, the coefficient of regression for Work Empowerment is 0.359, for Effective Leadership is 0.35 and for Empowerment is 0.096. All have a significant impact on the Satisfaction level of Teachers.

3. Component correlation matrix (Table 4.5), shows the highest correlation of 0.200 only which is between components 2 and 3 . 


\subsection{Conclusion}

1. The major factors affecting retention of teachers in management institutions in Bengaluru are i) Work Environment ii) Effective Leadership iii) Empowerment

2. Effective leadership, Work Environment and Empowerment make a significant impact on the satisfaction of teachers in Management Institutions.

3. To retain teachers in Management Institutions focus more on the work environment such as support given to teachers, strategies for promotion and even physical facilities.

\section{References}

Ahmad, N. and Abdul R. (2004) Job Satisfaction among School Teachers. The educational review, 47(8), 144-148.

Akram, A. A. (2012). Impact of Financial Rewards on Employee's Motivation and Satisfaction in Pharmaceutical Industry, Pakistan. Global Journal of Management and Business Research, 12 (17), 44-49.

Castillo J. X. and Cano, J. (2004).Factors explaining job satisfaction among faculty. Journal of Agricultural Education, 45(3), 65-74.

Manimalar,R. and S. Sudha. (2016). Corporate Ethical and Legal Responsibility: Effect of CSR on Customer Trust and Brand Loyalty. Prabandhan: Indian Journal of Management. 9(6), 156-167.

DOI: $10.17010 /$ pijom/2016/v9i6/94957

Mawoli, M.A., Babandako, A.Y. (2011). An evaluation of staff motivation, dissatisfaction and job performance in an academic setting. Australian Journal of Business and Management Research, 1(9), 1-13.

Mishra.U.S., Patnaik, S. and Mishra, B.B. (2016). Role Optimism on Employee Performance and Job Satisfaction. Pradhan: Indian Journal of Management. 